\title{
Artelogie
}

artelogie Recherche sur les arts, le patrimoine et la littérature de l'Amérique latine

$8 \mid 2016$

Transgression dans les arts / transgression des arts

\section{Todo se transforma: transferencia medial y precariedad en el arte chileno actual}

\author{
Lina X. Aguirre
}

\section{OpenEdition \\ Journals}

Edición electrónica

URL: http://journals.openedition.org/artelogie/555

DOI: $10.4000 /$ artelogie. 555

ISSN: 2115-6395

Editor

Association ESCAL

\section{Referencia electrónica}

Lina X. Aguirre, «Todo se transforma: transferencia medial y precariedad en el arte chileno actual », Artelogie [En línea], 8 | 2016, Publicado el 26 enero 2016, consultado el 09 mayo 2019. URL : http:// journals.openedition.org/artelogie/555; DOI : 10.4000/artelogie.555

Este documento fue generado automáticamente el 9 mayo 2019.

Association ESCAL 


\title{
Todo se transforma: transferencia medial y precariedad en el arte chileno actual
}

\author{
Lina X. Aguirre
}

\begin{abstract}
The art of the transfer: one transports data or signs from one point to another, and this act is more expressive of our era than any other. Transformation, transcoding, passage, and normed displacement are the figures of this contemporary transferism.

Nicolas Bourriaud (The Radicant)
\end{abstract}

1 En su análisis sobre la precariedad en el arte contemporáneo, el crítico y curador francés Nicolás Bourriaud señala que en medio del consumismo promovido por la globalización, el cual atenta contra todo lo que es durable, se está desarrollando una cultura basada, ya no en la durabilidad, sino precisamente en la precariedad. Esta condición /sensación se asocia hoy con la incertidumbre y la escasez de estabilidad generada por la flexibilidad que paradójicamente rige el sistema económico globalizado, y del cual se desprenden configuraciones subjetivas y sociales igualmente inseguras y móviles. Al respecto, dice Bourriaud que el arte contemporáneo deriva sus medios y formas de la precariedad que se experimenta en lo que Bauman denomina una "modernidad líquida", donde todo es transitorio, desechable, renovable (BOURRIAUD, 2009a : 23). De allí la inclinación de las obras contemporáneas hacia la inestabilidad, la transitoriedad y el movimiento "viatorización", como la llama Bourriaud, en que el artista se convierte en el prototipo del viajero, Homo Viator, "cuyo paso a través de signos y formatos resalta una experiencia contemporánea de movilidad, desplazamiento, cruce" (BOURRIAUD, 2009b: p113). Una de las formas en que el arte se "viatoriza", o se alinea con esta lógica del movimiento, es la transferencia o traducción, la cual consiste en el paso de los signos a través de formatos y medios, y en otras operaciones de transformación: cambios de dimensión, deformaciones, recomposiciones, recortes, procesos que incluyen fotografiar, fotocopiar, pintar, volver a copiar, escanear, enviar electrónicamente, imprimir, etc., para realizar 
una obra de arte que se sostiene, ya no como un resultado definitivo, sino como un paso más dentro de una larga cadena desjerarquizada e inconclusa.

Uno de los supuestos de los que parto es que la transferencia siempre involucra la tecnología. Esto no quiere decir que todos los artistas incorporen instrumentos digitales o altas tecnologías en su trabajo, sino que la presencia de la tecnología en las prácticas de la vida diaria es una de las razones que sostiene la intensificación de la transferencia y la transgresión de fronteras mediales estrictas. Las herramientas digitales nos ha educado en la transferencia y la modificación; nos permiten modificar de múltiples maneras la imagen como tal, cambiar su formato, ensamblarla con otros tipos de datos y someterla a operaciones que la rematerializan. Este modo de operación, casi invisible por demás, nos habitúa a la transferencia, pero además marca - como anota Bourriaud- nuestra forma de conceptualizar, representar, procesar y transmitir información (BOURRIAUD, 2009b: p133).

Movido por estas formas de conceptualización y representación, y por un interés en experimentar con todos los medios que la tecnología ha puesto a su disposición, el arte se ha volcado hacia la práctica de la transferencia, al punto de llegar a una situación donde los medios artísticos se combinan libremente y se superponen perdiendo su diferenciación, a lo cual la crítica Rosalind Krauss ha denominado condición post-medio (KRAUSS, 2000). En el pasado se trataba de fusiones identificables a simple vista, pero en la actualidad ha llegado a altos niveles de complejidad. En algunos casos es percibida por los espectadores, y las obras son presentadas como objetos particulares sin nexos con un medio específico; pero en muchos otros pasa desapercibida, precisamente porque la movilidad entre medios forma parte de una lógica que no es exclusiva del arte. En estos casos las obras finales se presentan como representantes de un medio: la pintura, la escultura, el dibujo, cuando en realidad provienen de largos procesos de pasaje y combinación. Esto último tiende a sostener fronteras entre los medios que no dejan de resultar artificiales, lo cual conduce a una percepción dividida de un arte que en realidad tiende a la generalización, al uso de amplias paletas de medios y procedimientos para la conformación de una intervención estética.

Este artículo reflexiona sobre la presencia e intensificación de la transferencia en el arte chileno de las últimas décadas, y sobre las tensiones y transformaciones que esta práctica evidencia entre el poder representativo de los medios, la disponibilidad de tecnologías y la capacidad reflexiva y contestataria del arte. Inicialmente propongo un breve recorrido que permite ver los matices de la transferencia desde los años 80, para luego detenerme en el trabajo de dos artistas emergentes actuales: Claudia Bitrán y Francisco Uzabeaga. Las obras "pictóricas" de estos autores abordan conceptual y formalmente la práctica de la transferencia y, en una problematización de las mediaciones tecnológicas, demuestran que la transferencia está asociada con modos de precariedad que van más allá de la forma y materialidad de la obra del arte sugeridos por Bourriaud, hacia los terrenos de la escasez material, la excesiva mediación y la inestabilidad de las relaciones interpersonales características de la sociedad globalizada. 


\section{La transferencia en el arte chileno de las últimas décadas}

5 En el arte chileno contemporáneo, la transferencia, tal como la he planteado aquí, es una práctica recurrente desde los años ochenta. Fue la Escena de Avanzada ${ }^{1}$ la que puso en funcionamiento una amplia serie de traspasos, combinaciones y movimientos entre medios que sin duda llevaron al arte chileno a la condición post-medio propuesta por Krauss. De acuerdo con la crítica Nelly Richard, la Avanzada plantea varias reformulaciones estéticas entre las cuales se encuentran "la transgresión de los géneros artísticos mediante obras que combinan varios registros de producción de signos [...] y que rebasan las especificidades de técnicas y formatos" (RICHARD, 2006: p105). No solo se trata de la incursión de nuevos géneros como el performance, sino de la extensión de los géneros hacia los bordes de sus territorios. Cada uno de los subgrupos que componían la Escena de Avanzada experimentaba con nuevos medios desplazando los medios anteriores, en una suerte de "carrera por el desplazamiento de los soportes" -como lo pone Eugenio Dittborn (GALENDE, 2007:143) quien pretendía extremar el gesto rupturista y dejar en claro el distanciamiento de posturas conservadoras.

6 Dentro de esta dinámica se abandona la pintura en su formato tradicional, no solamente por estar inserta en el circuito oficialista del que la Avanzada intenta distanciarse, sino por su aproximación subjetiva a la realidad y su base artesanal que le impediría articularse con la contemporaneidad. Como alternativa, se privilegia el código fotográfico, el cual se asume con capacidad de representar objetivamente la realidad, serializar la imagen e identificarla con las estéticas populares (RICHARD, 2006: p130).

Durante la transición a la democracia, la transferencia se convirtió en una práctica generalizada, pero adoptó rutas y sentidos distintos a los que tuvo en los ochenta. En el contexto postdictatorial, la labor artística estuvo marcada por la desconfianza frente a los pactos políticos y supuestos caminos de libertad abiertos desde el nivel institucional. Los artistas reaccionaron a esta desconfianza de dos maneras: algunos se negaron a seguir los "pactos de olvido" propuestos por la transición y generaron obras que ponían en discusión la historia y sus términos, la memoria y el olvido. Otros optaron por desligarse del aparataje discursivo y atender a preocupaciones técnicas y estéticas que habían sido dejadas de lado por preocupaciones políticas. Varios de los artistas de esta época se negaron a aceptar los pactos de olvido propuestos por la transición a la democracia y generaron obras que, a través de una secuencia de transferencias y experimentaciones mediales, ponían en discusión la historia y la memoria, y sus términos de representación. A diferencia de los artistas de los ochenta, quienes se enfocaron en las experiencias colectivas, en los noventa se dio una revaloración de la subjetividad individual, de los espacios cotidianos e íntimos, y una recuperación del cuerpo como territorio de placer. Todos estos, espacios que habían sido violentados por la dictadura y desplazados de los intereses de un arte que sentía responsabilidad de representación política.

El retorno a lo subjetivo, y la mayor autonomía asumida por los artistas con respecto a sus antecesores, contribuyó al reposicionamiento de la pintura y la hizo núcleo de múltiples operaciones mediales. Por otra parte, se comenzaron a utilizar materiales provenientes de contextos íntimos y familiares, tales como fotografías de propiedad de los autores, autorretratos y objetos domésticos que eran recontextualizados y resignificados a través de su incorporación, o de su representación mediada, en obras de arte. Por otra parte, los 
artistas de los noventa están expuestos a nuevas fuentes de información como revistas internacionales y a la posibilidad de viajar aprovechando nuevas oportunidades para artistas jóvenes. Adicionalmente, forman parte de una sociedad que ha sido totalmente transformada por el consumo y por el advenimiento de nuevas tecnologías. El Chile de los noventa está invadido de pantallas de nuevos tipos y de artefactos tecnológicos que transforman la vida cotidiana y que impulsan al arte en diversas direcciones. En las obras de esta generación se evidencia la urgencia por experimentar, por tratar de dar cuenta desde una diversidad de medios, de los cambios generados en la relación realidad/ imagen/tecnología. El píxel comienza a aparecer como seña de un nuevo tipo de transferencia, se desarrolla el género de la videoinstalación, se incorporan pantallas en obras con contenido artesanal, y se exhiben las mediaciones tecnológicas por las que atraviesan los productos finales. Dentro de los artistas de esta época que dieron uso intensivo a las transferencias mediales, están Voluspa Jarpa, Ignacio Gumucio, Natalia Babarovic, Alejandra Wolff, Judith Jorquera,Josefina Guilisasti y Jorge Cabieses.

Más recientemente, la inclinación hacia la transferencia se ha intensificado, convirtiéndose en una práctica común dentro de los procesos creativos de la mayoría de artistas jóvenes. Las obras de numerosos autores se plantean como cadenas de transferencias que se llevan a cabo en procesos más complejos que nunca, pues involucran una mayor cantidad de medios y un número creciente de referentes y fuentes de información, dentro de los cuales aparecen medios con alto contenido tecnológico como Internet y la fotografía digital, pero también medios artesanales como la animación stop-motion, la instalación y la pintura, los cuales se han enriquecido y renovado por su interacción con otros medios y lenguajes, como es el caso de las obras de Bitrán y Uzabeaga, en las cuales me detendré más adelante. Algunos artistas que exploran las transferencias en medios tanto artesanales como digitales de maneras interesantes son Pablo Ferrer, Pablo Serra, Antonia Cruz, Cecilia Avendaño, José Pedro Godoy, el colectivo de animación Diluvio, y la compañía de teatro-animación Maleza, entre muchos otros.

Dentro del panorama medial chileno, la pintura sigue teniendo un papel central, y el modo en que la transferencia, especialmente en su componente digital, la ha afectado y renovado, es digno de destacar. Como lo mencionaba antes, lo digital ha generado nuevas formas de conceptualizar y representar, pero además ha puesto a disposición de los artistas un sinnúmero de técnicas e instrumentos. Esto ha llevado a una mayor experimentación con procesos técnicos y en general a una prolongación del proceso creativo, en el sentido en que el proceso previo a la pintura incluye más pasos asociados a otros medios, como por ejemplo la toma o búsqueda de fotografías digitales, y procesos técnicos de ensamblaje, edición, iluminación e impresión digital, así como transposiciones, distorsiones y superposiciones. La prolongación del proceso podría relacionarse con un deseo, no solo de explotar los recursos disponibles, sino de obtener cierta estabilidad en medio de un contexto altamente cambiante. Con esta última afirmación quiero sugerir que el proceso creativo, expandido a voluntad, se convierte en una suerte de refugio donde el artista encuentra cierta permanencia. Para varios de los pintores chilenos cuyos procesos creativos he estudiado, la expansión del proceso permite la construcción de familiaridad dentro del proceso mismo, la sensación de experticia en un camino de permanente experimentación; y la vez, se plantea como una oportunidad de comprensión de las posibilidades de la pintura dentro del panorama amplio de técnicas artísticas y prácticas visuales cotidianas. Es posible que en el proceso creativo de los pintores actuales el componente puramente pictórico haya perdido importancia frente al 
peso de otros procedimientos, pero creo que la alta reflexividad técnica y de sentido que rodea esta redistribución, revitalizan y pueden asegurar, al menos en un aspecto, la validez de la pintura como forma de representación visual en la actualidad.

\section{Claudia Bitrán: banalidad y transitoriedad en el exceso}

11 A lo largo de su obra, Claudia Bitrán realiza transferencias del medio de la fotografía digital a lo pictórico, cuestionando y llevando a su límite la particularidad de cada medio. Con su énfasis en el acto del registro fotográfico y su proliferante trabajo serial, la artista llama la atención sobre la inestabilidad que lo digital le impone a nuestra relación con la realidad y con la imagen. A través de procedimientos pictóricos intenta emular el registro fotográfico resaltando la banalidad y la transitoriedad de la imagen en la actualidad.

12 La primera exploración de Bitrán sobre el registro fotográfico digital tiene lugar en la obra De manera (2009). Para la realización de este trabajo la artista escribe en Google una frase inventada por ella: "La vecina fue violada mientras Stan regaba", y realiza una búsqueda de imágenes. De los millones de fotografías obtenidas a partir de esta frase, selecciona cincuenta al azar y las pinta una al lado de la otra en varias tiras, repitiendo algunas fotos con leves variaciones. Fotografías de vacaciones, fiestas, reuniones grupales y momentos cotidianos priman en la obra. Cada tira permite suponer una narrativa, pero el hecho de que haya imágenes repetidas revela el carácter ficticio de las narrativas y la escasa importancia que tiene cada foto dentro de su conjunto. El ejercicio resalta la multiplicidad de la representación versus el carácter singular del criterio que la genera, así como la indiferenciación hacia la cual tiende la imagen fotográfica en la actualidad.

En su obra Dramatic Holidays (2009), Bitrán pasa a trabajar más directamente con el acto del registro y explora con mayor profundidad los problemas de la proliferación y la indiferenciación. El proceso creativo de la obra comienza con la realización de un viaje vacacional de Bitrán y sus amigos a Argentina. Con cámaras diferentes y sin ningún tipo de indicación, cada uno de los cinco viajeros hace el registro fotográfico del viaje. Al final, Bitrán recolecta alrededor de tres mil quinientas fotos de las cuales elige quinientas al azar y las pinta directamente de la pantalla del computador utilizando un estilo sintético y rápido. En su exhibición ${ }^{2}$, las quinientas pinturas son dispuestas sobre un muro a manera de cuadrícula sin que se pueda encontrar un orden cronológico o cromático ; a pesar de su disposición perfectamente alineada la obra se presenta como un caos visual por el que resulta difícil navegar.

El proceso de registro necesario para la realización de la obra evidencia cómo la práctica de la fotografía aficionada facilitada por los aparatos digitales de captura de imagen ha llevado nuestra relación con la realidad percibida de una relación fluida a una relación fragmentaria, discontinua. La creciente capacidad de los dispositivos de memoria de las cámaras fotográficas ha transformado radicalmente el registro fotográfico de los eventos cotidianos. En la época de la fotografía análoga había que controlar la cantidad de fotografías que se tomaban pues había una limitación material en el registro, mientras que en la actualidad cada fotógrafo cuenta con la posibilidad de tomar fotos casi de manera ilimitada. Esta posibilidad implica que la realidad se experimenta como un conjunto de instantes interrumpidos por el acto del registro, y que una buena parte del tiempo esa realidad se percibe a través de la mediación tecnológica de la cámara, pues la abundancia de medios desencadena un interés por registrarlo todo. A causa de la fijación en el registro, en el viaje de Dramatic Holidays se interrumpen la percepción del tiempo y 
del espacio, pero también las relaciones sociales y los afectos implícitos en el evento del "viaje de amigos". Aquí la precariedad tiene que ver, no con la escasez económica como una de las principales fuentes de inestabilidad en la globalización en Latinoamérica, sino con los efectos desestabilizadores de la abundancia, en este caso en el plano de la imagen, sobre nuestras relaciones con la realidad y con los otros.

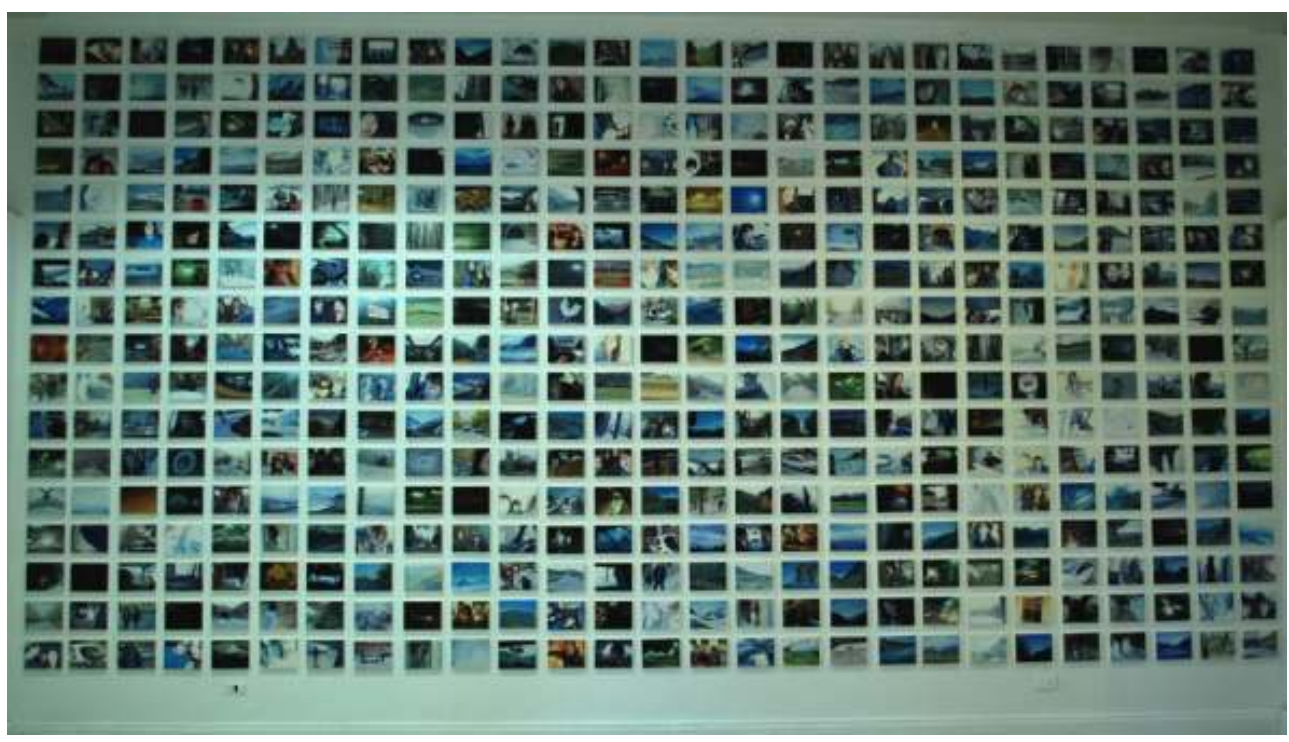

óleo sobre tela. $30 \times 20 \mathrm{~cm}$

Imagen cortesía de la autora [Claudia Bitrán]

15 Por otra parte, la instalación montada a partir de las quinientas pinturas revalúa la idea del viaje como una instancia de descubrimientos excepcionales que deben ser capturados a través de la fotografía. Las pinturas muestran un registro de todo, desde los momentos en que se comparte entre amigos, pasando por el paisaje, hasta objetos o escenarios indiferenciados. Gracias a la gran cantidad de imágenes, a la abundancia de tomas imperfectas que traicionan los estándares de la pose y la composición tradicionales, y al procedimiento rápido y sintético empleado para transferirlas a la pintura, la jerarquía entre las imágenes se pierde y todas quedan reducidas al mismo nivel de importancia. Así, el viaje es replanteado como una experiencia banal, como una trayectoria sin objetivo y sin resultados; vaciado en su faceta de búsqueda solo le queda su sentido de movilidad, de desplazamiento.

Estas características: banalidad y movimiento, son acentuadas a través de elecciones formales que apuntan a la dispersión de la sensación y la indiferenciación visual. Aquí resulta útil emplear dos conceptos propuestos por Gilles Deleuze en su libro Francis Bacon: the Logic of Sensation : lo figural y el movimiento forzado, los cuales tienen que ver con la producción de sensación en la pintura. El primero de ellos, lo figural, es planteado por Deleuze en oposición a lo figurativo. Una figura, según Deleuze, es una forma conectada a la sensación, y que transmite la violencia de esta sensación directamente al sistema nervioso (DELEUZE, 2003: xiii). En la pintura de Bacon, el cuerpo humano juega el rol de la figura, pues "funciona como el soporte material o marco que sostiene una sensación precisa". En Dramatic Holidays no es posible identificar figuras; la razón es que buena parte de las imágenes corresponden a tomas en movimiento, otras son imágenes 
indeterminadas o con encuadres en los cuales falta una forma protagónica que sea capaz de servir como soporte a la sensación, de conformarla y concentrarla. Cuando aparece el grupo de amigos, por ejemplo, sus rostros suelen estar en los bordes de la imagen o sus cuerpos son enfocados desde una gran distancia. Por otra parte está la baja vibración y la tonalidad predominantemente azul de las imágenes, lo cual se debe a que Bitrán pinta directamente de la pantalla del computador. La pantalla sirve como filtro que obra un aplanamiento adicional sobre las imágenes al homogenizarlas cromáticamente, reduciendo su potencial de sensación. En ausencia de figuras, la sensación se dispersa sobre la superficie de la obra y el tránsito por visual se convierte en un tránsito desafectado que deja clara la banalidad del viaje.

El segundo concepto que vale la pena considerar es el de movimiento forzado. Para Deleuze, según lo explica el filósofo Daniel Smith en su artículo "Deleuze's Theory of Sensation : Overcoming the Kantian Duality," el movimiento forzado o síntesis disyuntiva es el tipo más complejo de síntesis de sensaciones presente en la obra de Bacon. Se trata de la distensión o desviación de sensaciones, lograda principalmente a través de la serialidad -la estructura tríptica en el caso de Bacon. "Es porque en ellos (los trípticos) las Figuras separadas alcanzan una amplitud tan extraordinaria entre ellas que los límites de la sensación se rompen: la sensación no depende más de una Figura per se, en cambio el ritmo intensivo de fuerza como tal se convierte en la Figura" (SMITH, 1996: 47, cursiva en el original). Lo que sostiene la sensación, entonces, es la amplitud, la dispersión espacial. El movimiento forzado hace visibles las trayectorias que hay entre los elementos y las líneas de fuga que éstos trazan, y liga las sensaciones a esta necesaria movilidad. En Dramatic holidays el tamaño de la serie no le permite al espectador enfocarse en una imagen, sino que lo obliga a transitar y a encontrar líneas de fuga. En este movimiento, el espectador, acostumbrado a pensar el viaje como una narrativa, puede llegar a conformar precarias narrativas siguiendo variadas rutas dentro de la obra. Sin embargo, sea cual sea la ruta que se tome, la observación siempre lleva a imágenes indeterminadas, espacios vacíos, objetos fuera de encuadre, paisajes monocromos. La imposibilidad de trazar narrativas y el reiterado encuentro con lo indeterminado genera una sensación de desorientación e inestabilidad que se acentúan con el tamaño desmesurado de la serie. De esta manera, la obra convierte el viaje vacacional y su narrativa en un desplazamiento errático y desesperado. Dramatic holidays desecha la anécdota y rescata el viaje como movimiento.

Es así, a través del énfasis en el movimiento, como la obra se "viatoriza", es decir se sintoniza con las formas del viaje que Nicolás Bourriaud nota como una de las características más frecuentes en el arte bajo el régimen estético precario. De acuerdo con Bourriaud,

El viaje se ha convertido en una forma por sí mismo, el portador de una matriz visual que está reemplazando gradualmente la frontalidad publicitaria del Pop Art y la enumeración documental del arte conceptual, para citar dos formatos aún ampliamente usados en el arte de hoy (BOURRIAUD, 2009b: 113).

19 Dramatic holidays se distancia de estas dos aproximaciones al propiciar una mirada móvil, y al presentar una recolección desordenada de instantes que en su banalidad e inconexión no alcanzan a establecerse como documentos. Lo que prima en la obra es el viaje como paso a través de instantes y formas y el involucramiento sensorial del espectador en tal dinámica.

20 Como queda claro, Dramatic holidays se basa en estrategias formales que operan a través de la sensación. La obra banaliza lo representado y lo lleva a la indiferenciación al tiempo 
que acentúa lo intensivo, lo que puede ser sentido, como por ejemplo la vibración del color o la interacción entre los cuerpos o elementos que componen la obra. De esta manera se hace perceptible el movimiento, y surgen las sensaciones de desorientación e inestabilidad que he mencionado. Pero la obra también produce sensación de otra manera, y es a través de su materialidad. Almacenadas en un computador, las fotografías tienen una existencia fantasmal, están, como lo afirma el crítico Michael Rush, fuera del tiempo y el espacio (RUSH, 2005: 8). Por el contrario, al ser materializadas en la pintura e instaladas en el muro, adquieren una presencia sobrecogedora, pues modifican el espacio radicalmente y a una escala que supera ampliamente la del cuerpo humano. Debido al tamaño de la instalación cientos de cuadros quedan fuera del alcance visual directo del espectador, y por lo tanto de su atención, lo cual los hace perder especificidad y convertirse en una masa de imágenes inaccesibles y sin significado. Las imágenes se hacen prácticamente invisibles para el espectador en términos de significado, pero gracias a su presencia material, siguen siendo percibidas como perturbaciones del espacio. Todos los cuadros que el espectador no alcanza a ver directamente se convierten en una suerte de archivo -cúmulo de información al que no tenemos acceso directocuya presencia, a diferencia de los archivos digitales, es sentida y comprendida como exceso. Así, al proponer una relación inestable con el espectador, una mirada parcial y oblicua, la obra hace perceptible lo que usualmente es imperceptible en el régimen visual dominado por lo digital: el exceso de la práctica fotográfica actual y el caos visual que está oculto tras los sistemas de archivo.

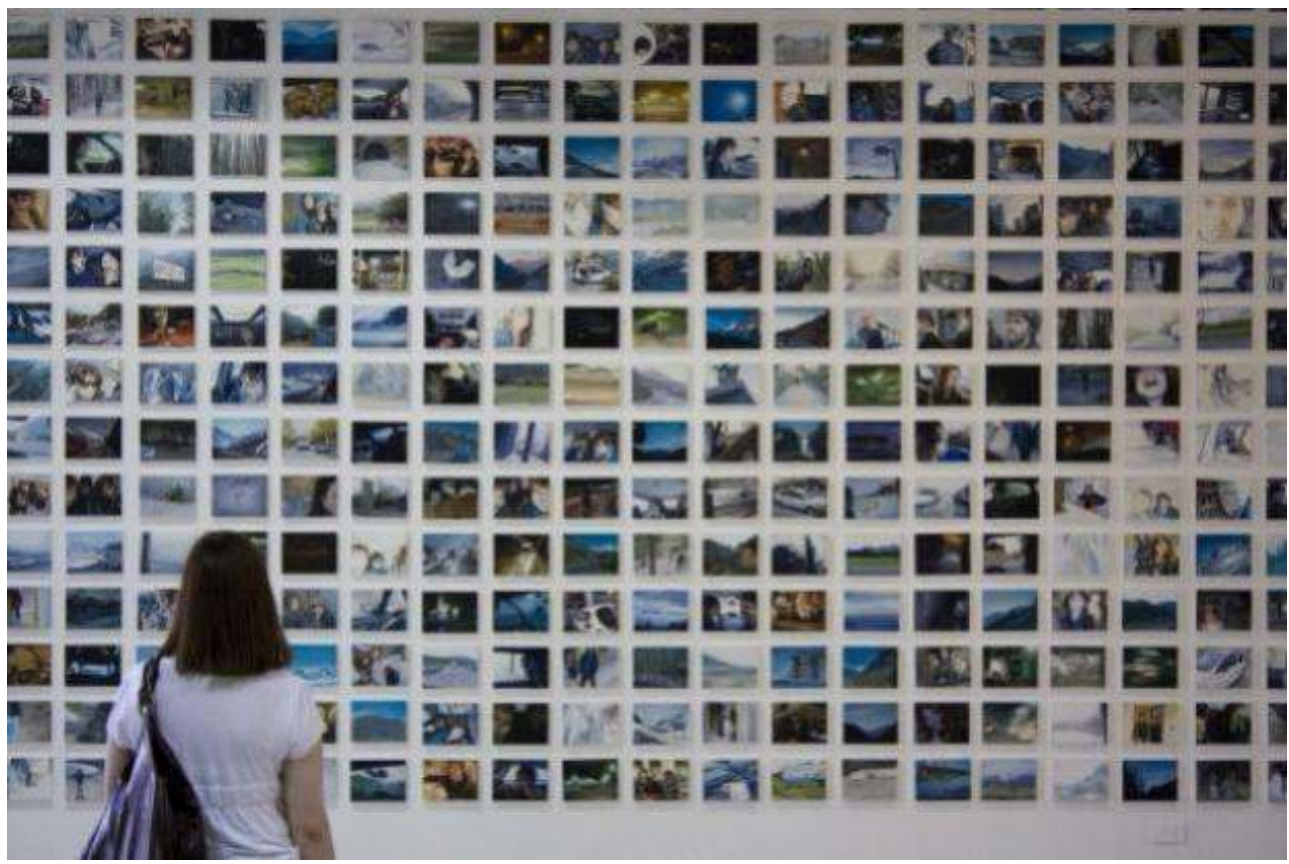

óleo sobre tela. 30×20 cm

Imagen cortesía de la autora [Claudia Bitrán].

21 Ahora quisiera tratar otro aspecto del registro fotográfico digital al que Bitrán dedica particular atención. Se trata de la existencia de diversos estereotipos en la práctica de la fotografía aficionada. La decisión de Bitrán de que el viaje sea registrado por varias personas y no por una sola busca intensificar la proliferación, pero también apunta a la 
búsqueda de patrones en la toma de fotografías de viajes de placer. Las tres mil quinientas fotos almacenadas le permiten a Bitrán confirmar:

las cosas que uno mira cuando se va de viaje, o que todo el mundo mira cuando se va de viaje, los estereotipos que tenemos de las fotos de deben tomar los amigos cuando la están pasando bien. Me di cuenta que todos los que tomaban las fotos miraban lo mismo, que todas las fotos miraban de la misma manera. La cultura popular está impregnada en todos nosotros. Todos sacaban la foto por la ventana con las gotitas de agua, el joven solitario en medio del paisaje, los amigos justo riéndose, todos las mismas, desde cinco cámaras distintas (BITRÁN, Entrevista personal, Agosto 23, 2010).

Considerando las similitudes en los encuadres, las poses, las composiciones cromáticas y los objetos fotografiados, Bitrán elige quinientas fotografías aleatoriamente y comprueba que los patrones se mantienen. Podríamos suponer que al ser transferidas a la pintura, al ser objeto de la atención y el trabajo manual de la artista las imágenes ganarían cierta singularidad, cierta unicidad, pero Bitrán anula dicha posibilidad al realizar la transferencia a la pintura con una paleta restringida de colores y procedimientos pictóricos que reducen aún más la diferenciación de las imágenes. Por ejemplo, pinta todos los paisajes de la misma manera e incluso de modo secuencial, convirtiéndolos en parte de una serie repetitiva. De esta manera, la artista deja clara la primacía de los estereotipos en los repertorios actuales de representación y la dificultad de transformarlos o desmontarlos, incluso desde medios poco tecnificados como la pintura.

Después de Dramatic holidays Bitrán continúa profundizando en su estudio sobre el estereotipo a través de series de pinturas por encargo y de la transferencia a la pintura de fotografías de personas que no se conocen entre ellas. La permanencia de patrones de composición y color en estas imágenes comprueban que nuestra mirada está capturada por convenciones desarrolladas recientemente gracias a la posibilidad de un registro sin restricciones, y que lo cotidiano y lo trivial ocupan lugares centrales en la representación fotográfica aficionada en la actualidad. 


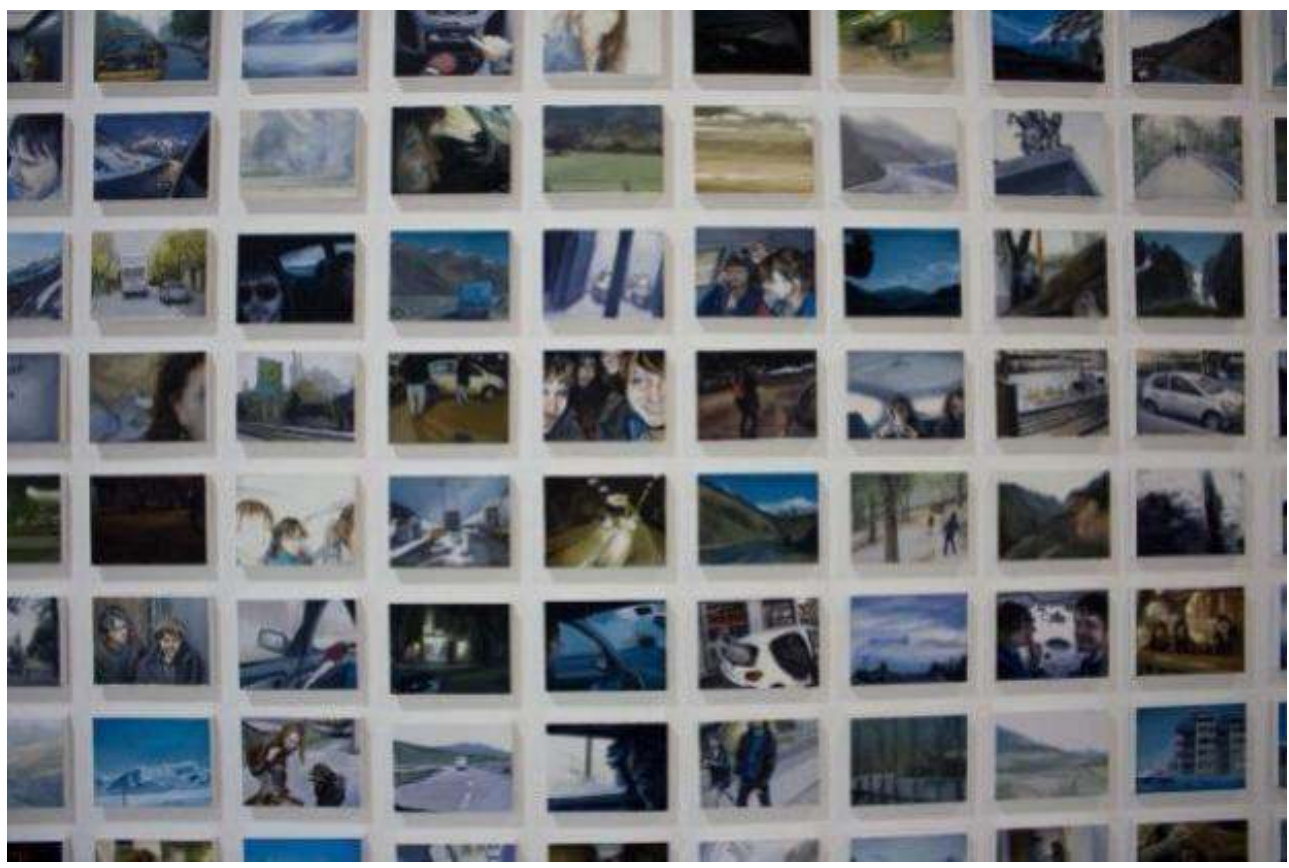

óleo sobre tela. $30 \times 20 \mathrm{~cm}$

Imagen cortesía de la autora [Claudia Bitrán].

Al transferir las fotografías al medio pictórico, Bitrán trata de conservar los niveles de importancia que las imágenes tienen en su registro original y su bajo nivel de diferenciación. En este sentido, su práctica pictórica se distingue de la de varios autores chilenos para quienes la transferencia de la fotografía a la pintura es una forma de valorizar la imagen y proveerla de un carácter único. En la obra de Bitrán la pintura es, ante todo, una manera adicional de procesar la imagen, una reproducción más en una cadena de reproducciones, que se conserva proliferante e indiferenciada. No hay jerarquías verticales entre lo fotográfico y lo pictórico, sino una horizontalidad que da cuenta de una nueva relación con la imagen, una relación más fluida, pero más insegura, en la medida en que se desprende de las convenciones tradicionalmente asociadas a cada medio.

Con la finalidad de acentuar la horizontalidad de la jerarquía entre lo fotográfico y lo pictórico y la relación entre ambos medios, Bitrán intenta imprimirle a la imagen pictórica las mismas características del registro fotográfico. Las pinta rápidamente, intentando alcanzar la velocidad de la captura digital, pero además las pinta, corta y ensambla en serie, imitando de forma rudimentaria un proceso industrial. El resultado, sin embargo, no es el deseado, pues lo pictórico, al ser abordado desde la síntesis, revela más que nunca su carácter manual, la limitación de su paleta de color y su diferencia con la alta definición y el acabado pulido de la imagen digital. Desde mi punto de vista este gesto intenta, irónicamente, mostrar al pintor como un operador de la imagen que busca actualizarse e insertar su forma de trabajo dentro de los actuales mecanismos de producción y manipulación digital. No se trata de desvalorizar a ninguno de los medios, sino de mostrar, a través de procedimientos pictóricos, que la pintura, para mantener un lugar dentro del actual régimen de la imagen, necesita integrarse con otros medios y entender su potencialidad y sus limitaciones frente a ellos. 


\section{Francisco Uzabeaga: transferencia del defecto}

La obra pictórica de Uzabeaga está guiada, como la de Bitrán, por experiencias personales y por su propia relación con la imagen. En su trabajo, sin embargo, no se aborda lo cotidiano, sino las imágenes del canon pictórico que le han servido al artista como referentes en su aprendizaje del arte. Con el ánimo del imitador, del que quiere aprender cada trazo, cada manera de los grandes pintores, Uzabeaga reproduce algunas de las grandes obras de la pintura universal de manera cuidadosa, sin dejar escapar ningún detalle. Lo irónico es que la transferencia no se realiza a partir de las obras mismas, ni de reproducciones fidedignas, sino a partir de reproducciones de baja calidad como aquellas que aparecían en los suplementos de los diarios durante los años de estudiante del artista. En las revistas utilizadas por Uzabeaga la técnica litográfica de impresión y la baja calidad del papel resultan en numerosas distorsiones que afectan a la imagen de manera profunda en su composición, sus características cromáticas y su iluminación, entre otros aspectos. Los bordes de las figuras son ambiguos, los colores aparecen separados evidenciando la mezcla de color de la técnica litográfica, los encuadres suelen estar alterados, y en algunos casos las imágenes aparecen invertidas con respecto a su posición original. Al valerse de la técnica de pintura cuadro a cuadro, la cual ha sido usada por algunos pintores hiperrealistas como el norteamericano Chuck Close, Uzabeaga es capaz de realizar una reproducción precisa en la cual resalta, ya no la maestría de la obra original, sino la imprecisión y acumulación de defectos de la revista de circulación masiva. Esta forma de transferencia evidencia la precariedad de la relación entre el artista y la imagen causada por la imposición de mediaciones cargadas de distorsiones. Precariedad en el sentido visual, la cual, sin embargo, tiene un trasfondo de pobreza y marginación. 


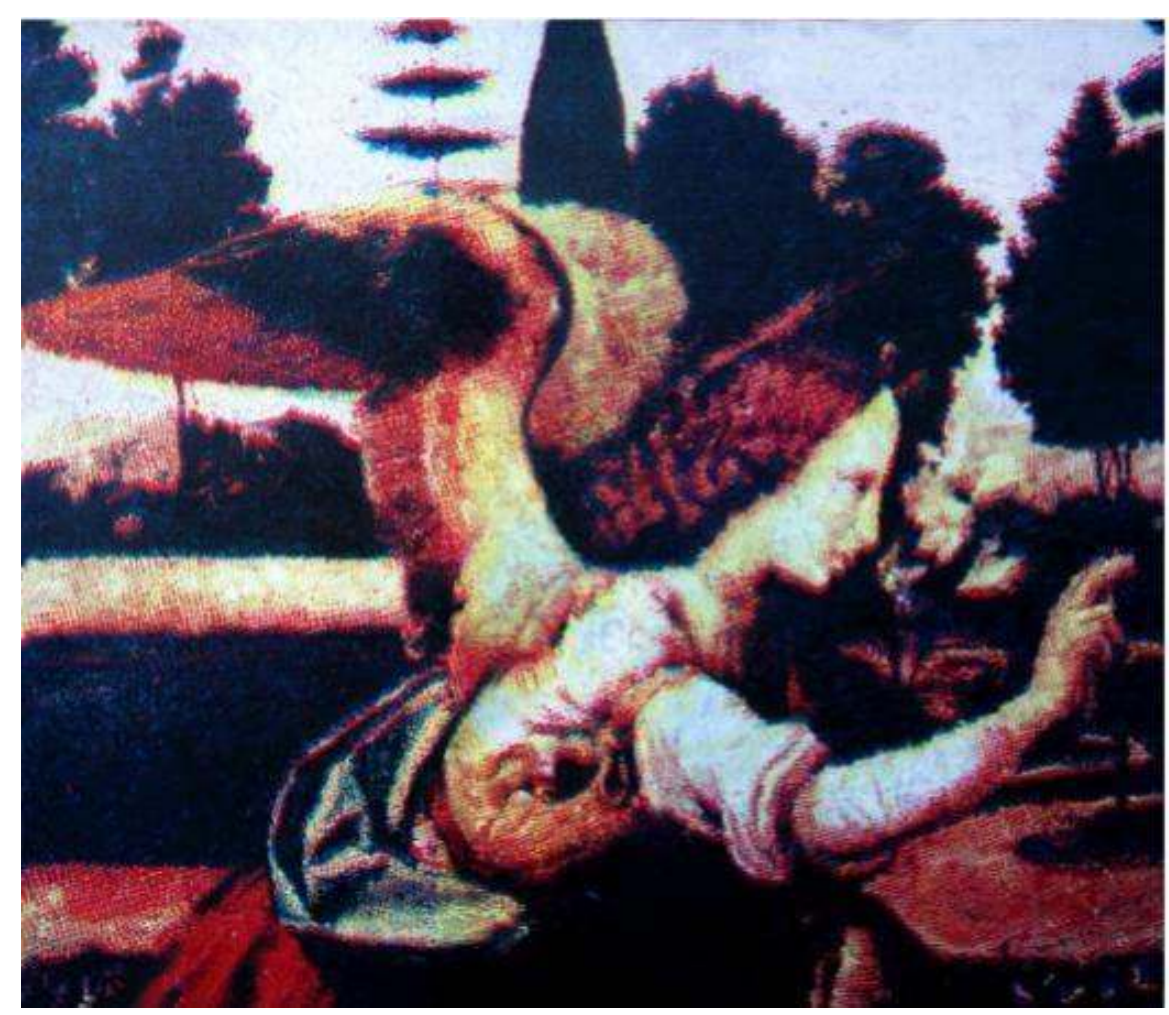

Óleo sobre tela. $45 \times 60 \mathrm{~cm}$

Imagen cortesía del autor [Francisco Uzabeaga]

A través del uso de revistas editadas en los ochenta, Uzabeaga intenta dar cuenta de las limitaciones de acceso a las imágenes que él, como artista proveniente de la clase trabajadora, tuvo en su educación artística:

En esa época yo veía los cuadros en revistas como Icarito, que era el complemento que venía con el diario La tercera; ahí aparecía todo, había números en que aparecía el resumen completo del arte chileno, todo en un solo número, o todos los museos chilenos... Esa era mi única forma de acceso al arte, resumida y de mala calidad... Cuando entré a la universidad me di cuenta de q ue las imágenes que había visto tenían los colores explotados, estaban recortadas o tenían la luz al revés. (UZABEAGA, Entrevista personal, Octubre 22, 2010)

Revistas como Icarito buscan poner a disposición de una audiencia infantil masiva lo que podría ser considerado como conocimiento de interés general. Especialmente en los años previos a la propagación de Internet, este tipo de publicaciones impresas pretendían cumplir una función de democratización del conocimiento, planteándose como complemento a los textos educativos y como sustitutos de enciclopedias y otras fuentes formales de información. Al enfocarse en la reproducción precisa de los defectos de las imágenes de estas publicaciones, Uzabeaga critica la calidad de estos intentos dirigidos a las clases trabajadoras, y muestra su proceso educativo y el de los jóvenes de su clase como un proceso defectuoso y marcado por la desinformación. Adicionalmente, al menos de manera indirecta, la obra de Uzabeaga cuestiona la formulación que las publicaciones masivas hacen del canon artístico universal y el papel que juegan en la percepción que se tiene en Chile sobre el arte local como algo distanciado o completamente ajeno a las grandes obras del arte mundial. El intento frustrado de reproducir las obras a partir de la 
distancia generada por las mediaciones, evidencia una suerte de extrañamiento, de desidentificación frente a una obra cuyo lugar de obra maestra, o su capacidad de representación universal están establecidos desde afuera y de manera arbitraria y poco comprensible para quien aprende y practica el arte desde un país periférico culturalmente como lo sigue siendo Chile en el mapa del arte mundial.

Es importante resaltar que a pesar de su origen humilde, Francisco Uzabeaga se educó en la Universidad de Chile, que es una de las escuelas de arte más importantes del país, y que su obra está inserta en el circuito más central al que puede acceder el arte joven local. Una de sus intenciones según él mismo lo ha expresado, es criticar las dificultades que los jóvenes como él, provenientes de las clases trabajadoras, tienen para acceder a una educación artística a lo largo de su vida. Él logró acceder a la universidad, pero critica el hecho de que muchos otros no logren hacerlo y no puedan acceder como artistas a ciertos niveles de legitimación y reconocimiento, pues el circuito local se caracteriza por una escasa movilidad entre los circuitos tradicionales-con gran sesgo académico y teórico, como ya se notó desde el arte de los $80-$ y los alternativos, donde sí tienen cabida propuestas no atravesadas por lo académico o la educación formal en el arte (UZABEAGA : 2010, Entrevista personal, Octubre 22). Actualmente, una vez inserto en el circuito tradicional del arte, Uzabeaga intenta mantener visible su lazo con una educación artística algo tortuosa, con los imaginarios estrechos y distorsionados de su infancia, para luego plantear un desafío al sistema a partir de la maestría técnica y el uso crítico de esos imaginarios iniciales.

La posición marginal en términos sociales desde la que Uzabeaga se presenta a sí mismo, se usa con un objetivo estético: evidenciar las posibilidades formales y las rutas excepcionales que puede tomar el arte originado en condiciones de marginación y escasez de medios. Su propuesta sugiere que la escasez ofrece nuevas posibilidades formales al arte chileno, pero, al establecer lo producido en medio de la escasez como una desviación, nunca logra una autonomía clara frente a los modelos provenientes de la historia legitimada y los circuitos centrales del arte.

31 En la obra de este autor, es claro que el modelo juega un papel importante. Se recupera, se cuestiona, se somete a reflexión a través del ejercicio cuidadoso de la reproducción hiperrealista. La transferencia es usada para intentar dotar al medio pictórico, más que a la imagen, de la importancia y la estabilidad visual perdida a través de la reproducción mecánica. En el proceso, la imagen gana valor al ser transferida a un medio artístico legitimado, pero como imagen no sufre ningún mejoramiento, sino todo lo contrario, adquiere los defectos adicionales propios del medio desde el cual se transfiere: la textura de la superficie del papel, las huellas de las letras impresas por el reverso de la hoja, los pliegues realizados por los lectores que han manipulado la revista. Este deterioro resulta contradictorio e incluso humorístico, pues hace ver el trabajo del artista como trabajo perdido -ya que se desperdicia reproduciendo el defecto- y a la pintura como un medio que no logra sobrepasar en calidad a las reproducciones técnicas. Es mediante esta contradicción que la obra de Uzabeaga cuestiona las jerarquías entre medios y evidencia la participación de la pintura dentro del régimen estético precario. La pintura, en las obras de este artista, se revela como un medio incapaz de rescatar a la imagen de su desestabilización en el sentido visual y en relación con un modelo original.

La desestabilización visual que sufre la imagen a lo largo de los procesos de transferencia conduce a la configuración de lo que Christine Ross denomina una "visualidad precaria". Como lo afirma Ross en la introducción del libro Precarious Visualities, la precariedad de la 
visualidad en el arte y en general en las culturas visuales contemporáneas tiene que ver con "la puesta en juego de estrategias que exigen del espectador una percepción a la que le falta seguridad, certeza y opticalidad" (ROSS, 2008: 9). Para Ross, este tipo de visualidad abandona el campo exclusivo de la visión y favorece modos de percepción más complejos en los cuales se interrelacionan los sentidos. Si tenemos en cuenta la aproximación de Deleuze a la sensación en la pintura, podríamos decir que una visualidad precaria implica un alto potencial de sensación, es decir, una capacidad de la imagen de involucrar sensorialmente al espectador de manera compleja. De acuerdo con Deleuze, estas síntesis de sensación se generan necesariamente a través de relaciones, especialmente a través de relaciones de color y entre los cuerpos presentes en la imagen (DELEUZE, 2003). Cuando una imagen contiene este tipo de síntesis, el espectador tiende a abandonar lo representado y a relacionarse con la imagen a partir de lo sentido.

Francisco Uzabeaga, El descenso, 2008

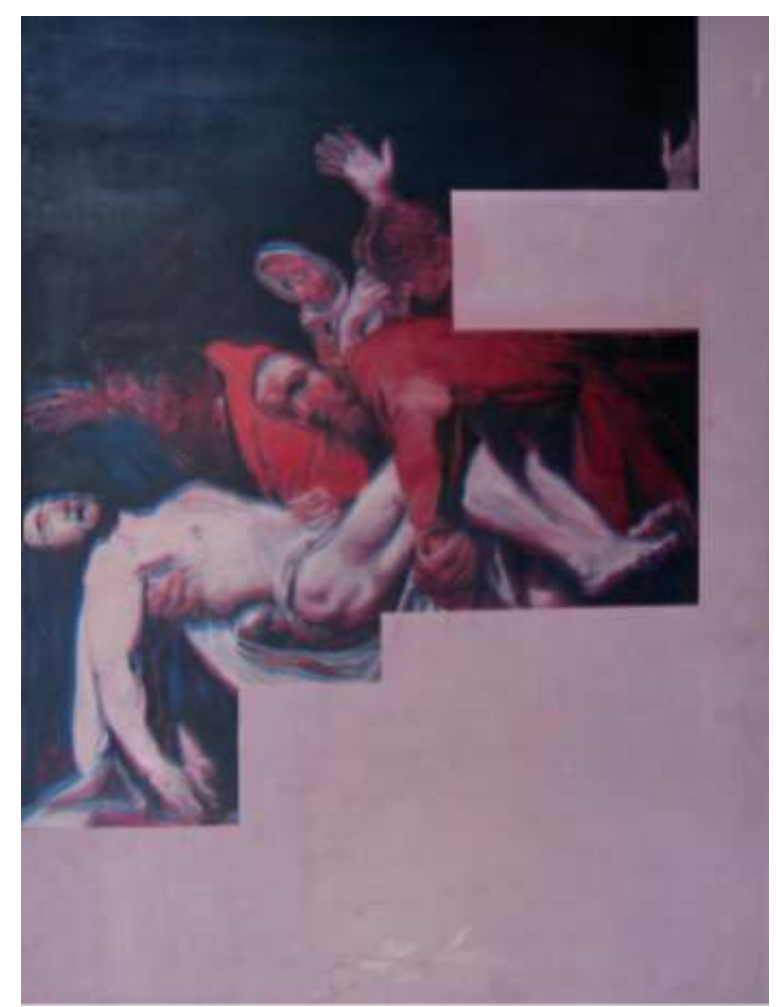

Óleo sobre tela. 180x148 cm

Imagen cortesía del autor [Francisco Uzabeaga]

En la obra de Uzabeaga, la distorsión impone una barrera para acceder a lo representado. En la distancia es posible tener una idea general de la imagen, pero las múltiples perturbaciones del color y la forma impiden dar cuenta de detalles o límites entre los diferentes elementos que la componen. Esto queda ejemplificado en cuadros como $\mathrm{El}$ descenso, donde la fuerte distorsión de los colores impide ver los detalles de los rostros y sus expresiones; incluso llega a borrar casi por completo uno de los personajes presentes impidiendo al cuadro adquirir sentido como representación religiosa. Debido a la distorsión, las Figuras, entendidas como cuerpos que concentran sensación, pierden sus límites y establecen relaciones ambiguas con los otros elementos del cuadro; sin embargo la sensación no se pierde, porque es sostenida por la fuerte vibración del color. Lo que se 
produce es una sensación de ruido, una incomodidad generalizada en la observación del cuadro. Por otra parte, la multiplicidad de detalles generados a partir de la distorsión genera una sensación de exceso similar a la que se produce en la obra de Bitrán a través de la multiplicidad de cuadros. Aquí la imagen es única, pero tiene tal abundancia de rasgos visuales que resulta imposible abarcarla y darle un sentido claro.

Obras como la de Uzabeaga y Bitrán buscan crear una relación inestable con el espectador. Le impiden acceder a la representación, lo desorientan, le ofrecen una observación incómoda, lo enfrentan al exceso en términos de escala, de objetos, de detalles. La pregunta es qué hay detrás de esto, por qué la pintura de los artistas emergentes de hoy se niega a congelar los eventos permitiendo una observación frontal y tranquila, y en cambio propicia una relación móvil y accidentada con la imagen. Creo que artistas como Bitrán y Uzabeaga intentan hacer perceptible la inestabilidad y mutabilidad que caracteriza a la imagen en una época de herramientas técnicas y transferencias, a través de un medio que puede asociarse a la estabilidad y permanencia. Pero más allá de lo puramente visual, sus pinturas constituyen una manifestación de la desorientación, incertidumbre y falta de fijeza experimentadas por los sujetos en la actualidad. La transferencia del defecto y la distorsión practicada por Uzabeaga es una forma contundente de materializar esa falta de fijeza y certidumbre. A través de una imagen inestable que surge de múltiples transferencias y que parece estar en pleno proceso de transformación, este artista representa la experiencia de la permanente transición y la imposibilidad de llegar a algo definitivo. Precariedad que en el contexto chileno de la actualidad está asociada con la globalización y su marco de regulación: el neoliberalismo. En las pinturas de Uzabeaga o de Bitrán no hay una denuncia del sistema económico, pero hay una visibilización de las condiciones generadas por él, y una demostración de la incomodidad e incertidumbre que generan. Las obras, como lo hemos visto, no tratan de abolir lo cambiante, sino que lo aceptan como un punto de partida y lo explotan formalmente; es decir que no intentan compensar la precariedad sino que buscan maneras de navegar en ella. En este sentido, las obras de Uzabeaga y Bitrán se encuentran alineadas con las otras obras visuales analizadas hasta ahora; todas ellas apuntan a la generación de estrategias para navegar la precariedad y al aprovechamiento formal de sus principios en nuevas propuestas creativas.

\section{BIBLIOGRAFÍA}

BOURRIAUD N.,"Precarious Constructions: Answer to Jacques Rancière on Arts an Politics", en A

Precarious Existence : Vulnerability in the Public Domain, Rotterdam, NA, 2009. p.20-36.

BOURRIAUD N., The Radicant, New York, Lukas \& Sternberg, 2009.

DELEUZE G., Francis Bacon: The Logic of Sensation, Minneapolis, University of Minnesota, 2003.

GALENDE F., Filtraciones I: conversaciones sobre arte en Chile (de los 60' a los 80'), Santiago, Editorial

ARCIS, Editorial Cuarto propio, 2007. 
KRAUSS R.E.; BROODTHAERS M., A Voyage on the North Sea: Art in the Age of the Post-medium Condition, New York, Thames \& Hudson, 2000.

RICHARD N., "La escena de avanzada en su contexto histórico-social.", en Copiar El Edén, MOSQUERA, G., Santiago de Chile, Ediciones Y Publicaciones Puro, 2006, p.103-119.

RICHARD N., Márgenes e institución arte en Chile Desde 1973, Melbourne, Art and Text, 1986.

Ross C., "Introduction: the Precarious Visualities of Contemporary Art and Visual Culture", en Precarious visualities : new perspectives on identification in contemporary art and visual culture, LAmoreuX, J., ASSELIN. O, \& Ross, C. (Eds.), Montréal, McGill-Queen's University Press, 2008.

RUSH M., New Media in Art, Londres, Thames \& Hudson, 2005.

SMITH D., "Deleuze's Theory of Sensation: Overcoming the Kantian Duality.", en Deleuze : A Reader, PATTON P. (Ed). Cambridge, Masachussets, Blackwell, 1996, p.29-56.

\section{NOTAS}

1. Con este rótulo, acotado por Nelly Richard, se conoce a un "movimiento de obras [...] perteneciente al campo no oficial de la producción artística chilena gestada bajo el régimen militar. Como el arte militante, la Escena de Avanzada se ubicó en una posición de rechazo dictatorial, pero a diferencia del primero, el cual buscaba mantener la continuidad del pasado, la Avanzada realizó su intervención a través de la ruptura con la tradición, estableciéndose como una vanguardia. Las obras del grupo se caracterizan por la dificultad de sus metáforas, su carácter elíptico, críptico y fragmentario, así como por el uso de lo fotográfico, el cuerpo en su sentido sacrificial y doliente, y su proximidad a los discursos teóricos postestructuralistas. La Escena de Avanzada incluye a artistas visuales como Eugenio Dittborn, Carlos Altamirano, Carlos Leppe y Lotty Rosenfeld, escritores como Raúl Zurita y Diamela Eltit, críticos como Nelly Richard y Adriana Valdés, filósofos como Ronald Kay y Pablo Oyarzún, entre otros.

2. Obra expuesta inicialmente en el Centro de Extensión de la Universidad Católica como parte de la exhibición de trabajos de grado de la escuela de arte, y posteriormente en el Museo de Artes Visuales como parte del Concurso de Arte Joven Cabeza de Ratón, 2009, donde obtuvo mención honrosa.

\section{RESÚMENES}

Este artículo analiza la transferencia, entendida como operaciones de transformación o de tránsito entre medios artísticos, en el arte chileno de las últimas décadas. La reflexión sobre esta práctica transgresora de las divisiones mediales tradicionales, se dirige hacia las tensiones y transformaciones que esta evidencia entre el poder representativo de los medios, la disponibilidad de tecnologías y la capacidad de intervención del arte en una sociedad marcada por la precariedad y la incertidumbre. Partiendo de la propuesta de Nicolás Bourriaud sobre el surgimiento, en la actualidad, de un régimen estético precario, propongo un recorrido que permite ver los matices de la transferencia desde los años 80 , para luego detenerme en el trabajo de dos artistas emergentes actuales. 
L'article traite du «transfert " au sens d'opération de transformation ou de transit entre des médias artistiques différents, dans l'art chilien de ces dernières décennies. Cette réflexion se concentre sur les tensions et les transformations que la pratique du transfert crée en relation avec le pouvoir de représentation de l'art, de la disponibilité de technologies et de la capacité de l'art d'intervenir dans une société marquée par l'insécurité et l'incertitude. En prenant comme point de départ la proposition de Nicolás Bourriaud sur l'émergence contemporaine d'un régime esthétique précaire, il propose une présentation qui permet d'observer les nuances du transfert depuis les années 1980, pour ensuite s'intéresser au travail de deux artistes contemporains émergents.

ÍNDICE

Mots-clés: art chilien, peinture contemporaine, globalisation, précarité, intermédialité, art et technologie, Chili

Palabras claves: arte chileno, precariedad, globalización, intermedialidad, arte y tecnología, Chile

\section{AUTOR}

\section{LINA X. AGUIRRE}

Institución: Pontificia Universidad Javeriana (Bogotá), Departamento de literatura Especialidad : $\mathrm{PhD}$ en literatura y cultura latinoamericana de The Ohio State University. Especialista en cultura visual y teorías culturales. 